\title{
El crédito del yo en el Persiles*
}

\author{
RANDI LISE DAVENPORT**
}

\begin{abstract}
Resumen
Este artículo documenta y analiza el uso del vocablo 'crédito' y sus derivaciones en el Persiles. Se presenta la hipótesis de que el uso frecuente y sofisticado de este vocablo en la última novela cervantina se podría relacionar con la constitución del sujeto y las construcciones del yo en la temprana Edad Moderna europea. Primero se ofrece un panorama diacrónico y temático del uso de este vocablo entre 1500-1750, señalando su auge en la época de Cervantes y un notable descenso hacia finales del Siglo de Oro. A continuación, se examina cómo el héroe de la novela cervantina se constituye y construye relacionándose con los demás personajes mediante el vocablo clave 'crédito' y sus derivaciones. Concluimos que el autor aprovecha este vocablo para con sus personajes precisamente porque viene cargado de sentidos múltiples de campos discursivos de acusada actualidad en su época, como el de la religión y el de la economía.
\end{abstract}

Palabras clave: Cervantes; Los trabajos de Persiles y Sigismunda; crédito; constitución del sujeto; construcción del yo; temprana Edad Moderna.

\section{Title: Credibility of the self in the Persiles}

\begin{abstract}
This article documents and analyzes the use of the word 'credit' and its derivatives in the Persiles. It presents the hypothesis that the frequent and sophisticated use of this word in Cervantes' last novel is related to the constitution of the subject and the constructions of the self in the early modern period. First, it offers a diachronic and thematic overview of the use of the word in the period 1500-1750, signaling its increase in the era of Cervantes and a notable decrease towards the end of the Golden Age. Secondly, it examines how the hero of the Cervantine novel constitutes and constructs himself relating to his fellow characters through the key word 'credit' and its derivatives. We conclude that the author made

* Este artículo tiene su origen en una comunicación presentada en el XIX Congreso de la Asociación Internacional de Hispanistas en Münster, Alemania, en julio de 2016, bajo la convocatoria temática de la constitución del sujeto y las construcciones del yo en la temprana Edad Moderna.

** UiT Universidad Ártica de Noruega. randi.davenport@uit.no / ORCID iD: https://orcid. org/0000-0002-1141-9785.
\end{abstract}


use of this vocabulary in constructing his characters precisely because it was charged with multiple meanings from fields of discourse of great actuality, like religion and economy.

Keywords: Cervantes; Los trabajos de Persiles y Sigismunda; Credit; Early Modern Constructions of Self; The Early Modern Subject.

\section{Cómo citar este artículo / Citation}

Davenport, Randi Lise (2019). «El crédito del yo en el Persiles», Anales Cervantinos. 51, pp. 161-178, https://doi.org/10.3989/anacervantinos.2019.008.

«Todo está en construcción durante los Siglos de Oro», escribe José Manuel Lucía Megías en el primer volumen de su biografía en tres tomos sobre Cervantes, La juventud de Cervantes, con el subtítulo muy a propósito: Una vida en construcción. Así nos lo recuerda el autor en su carta dedicatoria al lector:

Se construye en estos años la guerra en Europa, [...]. Se construyen en estos años nuevas reglas religiosas [...]. Se construye en estos años una nueva geografía, [...]. Se construye en estos años la cultura en Europa [...]. Se construye en estos años la vida a base de escritos, de papeles (2016: 15).

Podríamos añadir: se construye en estos años una nueva economía transatlántica con su influjo también en el discurso económico.

Todas estas construcciones se reflejan en la última obra de Cervantes, Los trabajos de Persiles y Sigismunda, historia setentrional (Madrid, 1617) ${ }^{1}$. Y también, según intentaré demostrar en este artículo: la novela de Cervantes participa en la construcción del yo como sujeto de esta temprana Edad Moderna europea cambiante.

A pesar de destacar el 'yo' en el título, este artículo no indagará la vía de la constitución del sujeto en su dimensión interior, tema que se ha estudiado ya, por ejemplo, en fructífera combinación con las teorías del dialogismo y del cronotopo bajtinianos ${ }^{2}$; tampoco se concentrará en la perspectiva genérica, como en la de literatura de viajes, que proporciona una posibilidad de ver cómo el yo se proyecta en el espacio; al contrario, este trabajo se propone simplemente explorar el vocablo crédito como nexo de relación entre los personajes del Persiles. Y a partir de ahí estudiar cómo el sujeto protagonista utiliza este vocablo en sus construcciones del yo en intercambio con los demás personajes.

1. Como resume tan sucintamente Tomás de Mercado en su Summa de tratos y contratos (1571): «De modo que cualquier mercader caudaloso trata el dia de oy en todas las partes del mundo, y tiene personas que en todas ellas les correspondan den credito y fe à sus letras, y las paguen, porque han menester dineros en todas ellas» (Libro Quarto, folio $11 \mathrm{r}$ ).

2. Ver por ejemplo Lozano-Renieblas (1998) y Deffis de Calvo (1990). 


\section{EL VOCABLO 'CRÉDITO'}

El vocablo ‘crédito’ está registrado en la lengua vernácula en España desde la época del Cantar del Mío Cid como indica Corominas ${ }^{3}$. Sin embargo, recién se nota un aumento considerable de su uso en la época denominada Modernidad temprana (tradicionalmente refiere a los años que van entre 1500 y 1650), si nos basamos en su recurrencia en los registros del Corpus Diacrónico del Español (CORDE) ${ }^{4}$. Carlos Romero, en la nota 8 al capítulo 12 del segundo libro de su edición revisada del Persiles, donde Periandro prosigue «su agradable historia y el robo de Auristela», señala que «Las fórmulas a base de crédito y cortesía son frecuentísimas en la literatura del Siglo de Oro» ${ }^{5}$, y remite como referencia a La perfecta casada de fray Luis de León y cita tres ejemplos más en el propio Persiles (II, 20, 415; III, 6, 490, y III, 12, 563). Esta nota de Romero confirma también mi impresión de la alta frecuencia de las expresiones con 'crédito' en la obra póstuma de Cervantes, impresión que luego encontró su apoyo en el sugestivo estudio de Steven Hutchinson Economía ética en Cervantes (2001). Comenta Hutchinson que:

El Quijote sería inconcebible sin el sutil juego de las variadas acepciones de creencia, crédito y otras nociones parecidas que afectan a la identidad de los personajes, a las relaciones entre ellos y -como ha demostrado Michel Moner- a toda clase de pactos narrativos (2001: 95).

Hutchinson examina en un breve capítulo titulado «Crédito personal» los aspectos de creencia y crédito que refieren al valor de los personajes en dicha novela ${ }^{6}$. Y, aunque no menciona el Persiles en dicho capítulo, corrobora mi sospecha de que el vocablo crédito merece mayor indagación que la simple observación de Romero ${ }^{7}$. Huelga precisar que al enfocarme en el vocablo

3. Corominas y Pascual (1980, vol. 2: 235) también señala que lo encontramos en el anónimo Libro del Cavallero Cifar del siglo XIV (1300-1305).

4. Más adelante se presentarán los datos recogidos, que también hemos adjuntado en su forma completa en el apéndice.

5. Cervantes (2004: 362). Todas las referencias a Los trabajos de Persiles y Sigismunda remiten a esta edición.

6. «Entiéndase "economía ética" como la economía de la ética, la ética como una especie de "economía". La economía ética se manifiesta casi por dondequiera que se mire, siempre con distintos tonos y colores, [...], este sistema se despliega como una "economía" en la que la valoración y las relaciones de "deuda" y "pago" generan infinitos modos de ser, estados de ánimo y comportamientos humanos» (2001: 21). Hutchinson parte de una interesante lectura de la Ética Nicomáquea de Aristóteles.

7. Obviamente sí hay una relación interesante entre 'crédito' y 'corte' ( $c f$. la traducción de Juan Boscán de El Cortesano de 1534 que tiene 6 casos de 'crédito': "Así que en encubrilla se ha de poner mayor diligencia que en ninguna otra cosa; porque, en el punto que se descubre, quita todo el crédito y hace que el hombre sea de menos autoridad» (I, 5, p. 103); «Que cuanto de esta manera, paréceme a mí que tampoco sería muy gran pecado dar también crédito en la forma del hablar al Policiano, a Lorenzo de Médici, a Francisco Diaceto y algunos otros que no dexan de ser toscanos y, por ventura, no de menor dotrina y juicio que fueron el Petrarca y el Bocacio» (I, 8, p. 117); «porque aquella fama, que es vista proceder de muchos buenos juicios, causa un cierto y firme crédito bueno, 
crédito no pretendo de ninguna manera presentar una 'metáfora global' que 'explique' todo el Persiles ${ }^{8}$. El objetivo es mucho más modesto: seguir una posible pista en el texto que nos introduzca en el mundo histórico de Cervantes.

Para cumplir con dicho objetivo debemos precisar cuáles son los campos discursivos de la sociedad de la época donde preferentemente opera este vocablo. Los diccionarios históricos y etimológicos nos proporcionan un primer panorama, donde destacan los campos de la religión y la economía, y lo que podríamos definir como 'el hombre en la sociedad'. Este último caso deja entrever el Diccionario de Autoridades cuando cita la obra de Juan Eusebio Nieremberg Obras y días, manual de señores y príncipes en que se propone con su pureza y rigor la especulación y ejecución política, económica y particular de todas virtudes (Madrid, 1629), que en el capítulo 5, «De la virtud de la fe», sostiene que «porque el que cree a otro hombre, no lo hace sin que acompañe a su crédito alguna razón que divise el bulto de la verdad» ${ }^{9}$. Lo que confirman las definiciones de Covarrubias y otros ejemplos del Diccionario de Autoridades, que inciden en indicar que 'crédito' es un vocablo con el que el sujeto se relaciona con los demás, oralmente o por escrito (ver el apéndice).

El hecho de que 'crédito' tenga una frecuencia alta en este periodo y un notable descenso después de mediados del siglo XVII, tal como lo registra el Corpus diacrónico del español, hace que merezca nuestra atención. Parece indicar la funcionalidad y necesidad de este término en el periodo. 'Crédito' / 'credito' (sin acento) en «todos los medios» se distribuye de esta forma en secuencias de 50 años entre $1500-1750^{10}$ :

el cual después, hallando los ánimos de aquellos que os tratan dispuestos y casi granjeados, fácilmente con las obras se mantiene y se mejora» (II, 3, p. 170); «tiniendo por determinado que no se puede recebir engaño en un crédito ganado por relación de tantos buenos juicios» (II, 3, p. 171); «y nunca diese tanto credito [sic] ni tanta parte a ningún ministro suyo, que le cometiese a él solo totalmente todo el gobierno; porque ninguno hay tan hábil que lo sea en toda cosa» (IV, 4, p. 329); «y así esle forzado para alcanzar algún conocimiento de las cosas, que vaya mendigando de los sentidos el principio dellas y por eso les da crédito, y tras ellos se anda y a ellos toma por guía, en especial cuando son tan poderosos que casi la fuerzan» (IV, 6, p. 340), (Castiglione 1984).

8. No se estudia el 'concepto' como idea fija, sino el 'vocablo', o la 'lengua en uso' tal como defiende Neil Kenny en su estudio sobre la 'curiosidad' en la temprana modernidad europea, Curiosity in Early Modern Europe: Word Histories (1998). Un libro reciente -de índole muy distinta al estudio de Kenny- del doctor en derecho y técnico fiscal del estado Francisco Fernández-Flores, relaciona el Quijote de Cervantes con el mundo económico de su tiempo, comprobando el buen conocimiento del alcalaíno en esta materia (2016: 410). En cuanto al Persiles, Aurora Egido ha realizado estudios exhaustivos sobre el significado del vocablo 'trabajos' en la obra $(1991,2004)$.

9. Diccionario de Autoridades I (1990: 652). (La cita de Nieremberg está en el folio 27v). En el primer apéndice a este artículo se ofrece un resumen de las entradas en Corominas, Covarrubias y el Diccionario de Autoridades.

10. Datos obtenidos el 21.9.2017. Huelga añadir que la distribución cronológica según las divisiones del corpus es de $21 \%$ de textos de la Edad Media ( $\approx 1250-1492)$, 28\% de los Siglos de Oro (1493-1713), y 51\% de la Época Contemporánea (1714-1974). 
1500-1550: 'crédito' 867 casos en 108 documentos, 'credito' 51 casos / 35 docs.

1551-1600: 'crédito' 1827 casos en 267 documentos, 'credito' 142 casos / 54 docs.

1601-1650: 'crédito' 1849 casos en 355 documentos, 'credito' 223 casos / 67 docs.

1651-1699: 'crédito' 520 casos en 83 documentos, 'credito' 98 casos / 15 docs.

1700-1750: 'crédito' 410 casos en 58 documentos, 'credito' 42 casos / 12 docs.

En estos mismos periodos se observa la siguiente variación en cuanto a cuáles géneros ocupan los primeros puestos de casos (según la clasificación de géneros de CORDE):

1500-1550: prosa histórica, prosa científica, prosa narrativa.

1551-1600: prosa científica, prosa histórica, prosa religiosa.

1601-1650: prosa narrativa, prosa histórica, verso dramático.

1651-1699: prosa histórica, prosa de sociedad, prosa científica.

1700-1750: prosa histórica, prosa didáctica, prosa de sociedad.

Una primera conjetura indicaría que hacia finales del siglo XVII el vocablo ya no es el preferido para establecer (o cuestionar) las relaciones entre personajes en la literatura de imaginación, o prosa narrativa, y que cada vez se circunscribía más a los campos discursivos de carácter científico, especialmente la economía en cuanto disciplina independiente ${ }^{11}$.

\section{‘CRÉdito’ EN EL PERSILES}

Si ponemos nuestra atención ahora en el texto de Cervantes, anotamos 24 casos del vocablo 'crédito' en el Persiles, y si añadimos los casos del verbo 'acreditar' y sus derivaciones, suman 26 casos más, es decir un total de $50^{12}$. Hutchinson comenta en su estudio que el origen común de «creer, confiar e incluso prestar» en el verbo latino credo «se manifiesta a menudo en las

11. Como señala Aaron Kitch en un libro sobre cómo autores ingleses del siglo diecisiete respondieron a los debates contemporáneos sobre comercio, cambio y moneda, la disciplina de la «economía política» se establece como un campo de conocimiento formal y propio en 1660 con los estudios de William Petty, precursor de Adam Smith. Sin embargo, el término se había acuñado ya en 1615 con la obra Traité de l'économie politique del 'economista' -y dramaturgo (amén de soldado y aventurero)- francés, Antoine de Montchrestien. El capítulo 5 del libro sobre 'crédito' y 'credibilidad' relacionado con el 'personaje' (character) en las comedias urbanas de Thomas Middleton, tiene cierta relevancia para nuestro propósito (Kitch 2009). Para la constitución de un lenguaje económico propio en el ámbito español desde el siglo XVI, remito al trabajo de Quirós García (2013).

12. En el apéndice se ofrecen todos los ejemplos. 
novelas de Cervantes donde, por ejemplo, creer y dar crédito suelen ser expresiones intercambiables» (2001: 95). El uso de expresiones con 'crédito' y 'acreditar' en el Persiles se distribuye entre todo tipo de personajes, con una ventaja para el narrador, sobre todo en los libros III y IV, con 5 casos de 'crédito' y 10 de variantes con 'acreditar'. Lo que se corresponde con lo ya señalado por Alban K. Forcione: que la posición central que el narrador establece en el libro II continúa en los dos últimos libros ${ }^{13}$. Santiago López Navia argumenta que en el Persiles - a diferencia de lo que ocurre en el Quijote- la instancia que él denomina 'el narrador principal' «se preocupa de reforzar la credibilidad de lo que nos transmite, anticipando en los pretendidos incrementos textuales transformadores las circunstancias que definen el sutil equilibrio entre la verdad y la imaginación» (López Navia 2004: 460).

Vamos a centrarnos en unos ejemplos concretos del uso de los vocablos 'crédito' y 'acreditar' en el texto, empezando por uno en el séptimo capítulo del primer libro, en la Isla Nevada, donde el protagonista septentrional le asegura al «bárbaro italiano» Rutilio que no tema no ser creído al contar sus muchas desgracias a pesar de ser «tan nuevas y tan extraordinarias»:
El bárbaro Antonio, dijo al bárbaro italiano, que, para entretener el tiempo y no sentir tanto la pesadumbre de la mala noche, fuese servido de entre- tenerles contándoles los sucesos de su vida, porque no podían dejar de ser peregrinos y raros, pues en tal traje y en tal lugar le habían puesto.
-Haré yo eso de muy buena gana -respondió el bárbaro italiano-, aunque temo que, por ser mis desgracias tantas, tan nuevas y tan extraordinarias, no me habéis de dar crédito alguno.
A lo que dijo Periandro:
-En las que a nosotros nos han sucedido nos hemos ensayado y dispuesto a creer cuantas nos contaren, puesto que tengan más de lo imposible que de lo verdadero (I, 7, 184).

Mi hipótesis es que no solamente le interesa al héroe-protagonista contar su propia historia y ejercitar su elocuencia, sino que también le importa que otros cuenten las suyas, como hace aquí Rutilio. Aunque es Antonio quien le pide a Rutilio contar su historia, es Periandro quien le extiende una especie de acreditación anticipada. Este intercambio de 'historias acreditadas' es una parte constitutiva de la novela y también de la construcción del sujeto en ella. Michel Moner ya había señalado, en el estudio citado por Hutchinson, que la 'reciprocidad' entre los personajes no es gratuita, sino que las palabras intercambiadas tienen un «valor de mercancía» ${ }^{14}$.

13. «In the final two books of the Persiles the narrator continues to occupy the central position that he appropriates for himself at the beginning of Book II» (Forcione 1970: 269). A su vez, José Manuel Martín Morán ha señalado «la presencia capilar de la voz del narrador que interviene desde el yo» en estos dos últimos libros (2008: 189).

14. Michel Moner (1989: 162). Este intercambio también ha sido comentado por Lukens-Olson: «Every stop along the way the two [protagonists] encounter others with whom they trade the stories of their plights» (2001: 51, la cursiva es mía). 
Hace ya tiempo que la crítica ha visto en Periandro-Persiles un héroe en transición entre épocas. En su estudio sobre La novela bizantina de la edad de oro (1996) Javier González Rovira resumía que «el Persiles representa la perfecta asimilación de los modelos clásicos por la cultura barroca, [...], de amplitud psicológica en la representación humana y de profundidad en la visión de la existencia como complicada peregrinatio vitae» (247). Mientras que Isabel Lozano-Renieblas, en su imprescindible estudio Cervantes y el mundo del Persiles (1998), nos muestra cómo esto se traduce en la creación del «tiempo interior»: los personajes cambian de estado mental según sufren la «duración temporal» por esperas, inseguridad y decisiones difíciles $(67)^{15}$. A diferencia de los héroes viajeros clásicos y medievales, comenta LozanoRenieblas, se resalta la importancia del «carácter del héroe» (146). Cervantes así individualiza a Periandro mediante las reacciones reservadas de varios de sus oyentes cuando cuenta su viaje, su palabra «despierta recelos y constituye un auténtico acto de autoheroificación, generando en el auditorio y en los lectores reiteradas reservas sobre su veracidad» (1998: 146). O, como resume Lozano-Renieblas en su estudio posterior: Cervantes aprovecha el héroe de las novelas de aventuras para crear un «héroe bicéfalo», uno que proyecta lo exterior $y$ lo interior, pero repartido entre Periandro para la dimensión exterior, y Auristela para la dimensión interior (2014: 51-63).

Carolyn Lukens-Olson, por su parte, propone que Cervantes cambia el héroe guerrero por un orador elocuente y prudente (2001: 51), aunque, según la autora, la mayoría de los críticos no reconocen o aprecian su capacidad de persuasión, tal como hace su auditorio en la novela (54). Unos años más tarde afirmará Michael Armstrong-Roche (2009) que, a pesar de haber demostrado todas sus proezas como héroe épico en el segundo libro, PeriandroPersiles no es un héroe épico clásico, espada en mano, sino más bien un héroe poeta, soñador y amante, más que guerrero y conquistador ${ }^{16}$.

Apoyándome en estas observaciones pertinentes de la crítica, quisiera llevar mis comentarios sobre el intercambio de historias acreditadas como constitutivo para la construcción del sujeto hacia otro lado en base a los siguientes aspectos: la historia como 'tarjeta de crédito del sujeto', y, el 'yo relacional' y el 'crédito relativo, o la relatividad del crédito', que se explicará a continuación.

15. Como bien se sabe la base teórica aquí es Bajtín y su teoría del cronotopo y la creación del 'tiempo interior' como categoría temporal nueva, resultado de la fusión de dos cronotopos distintos: el de aventuras y el de costumbres. Lozano-Renieblas también da referencias a Descartes Principios de filosofia I, 7 (distinción entre tiempo y duración, la categoría de tiempo está en el objeto, pero solo el sujeto puede pensarla), y a Locke An Essay Concerning Human Understanding (II, XIV y XV): el tiempo como una construcción de la mente, lo que propensa los «estados mentales» en la novela (1998: 67).

16. Esto también tiene implicaciones para la constitución del nuevo tipo de yo-gobernador en esta época de transición. Armstrong-Roche comenta cómo la tradición del espejo de príncipes se ve modificada por el sueño de Periandro sobre la «Sensualidad» como una fuente importante de las virtudes que Cervantes confiere a su héroe. Periandro emerge como el principal «contra-ejemplo» de barbarismo entre los personajes masculinos (2009: 168). Para una reciente interpretación del sueño en relación con Periandro como narrador-manipulador que termina derrocando y exaltando a la vez al héroe barroco, ver Julia D’Onofrio (2019). 


\section{LA HISTORIA COMO TARJETA DE CRÉDITO DEL SUJETO}

Al fijarnos en lo que contesta Periandro a la duda de Rutilio acerca de si le darán crédito o no, vemos que Periandro presenta una especie de letra de cambio ya que el grupo que él preside ha experimentado parecidas desgracias «nuevas» y «extraordinarias», como para estar dispuestos a creer lo que les tienen que contar. También podemos decir que el crédito que Periandro le otorga a Rutilio lo cobrará a todo el grupo más tarde, en la Isla de Policarpo (II, 10), cuando el protagonista empiece a contar los sucesos de su viaje. A pesar de que Periandro lo hace porque se lo pide Sinforosa, y no por 'voluntad propia', es obvio el gusto con que lo hace. Pero también se ve que tiene necesidad de las historias de los demás personajes en la construcción de la autoridad de su propia narración y de él mismo como sujeto. Lo vemos, por ejemplo, al instar al «cantor» enamorado portugués a contar su historia a pesar del cansancio que tienen todos a finales del capítulo 9 (199). Sin embargo, en este caso el comprobante de la credibilidad del noble y soldado portugués Manuel de Sosa Coitiño es su propia muerte, que él mismo pronostica al iniciar su historia: «Con más breves razones de las que sean posibles daré fin a mi cuento con darle al de mi vida, si es que tengo que dar crédito a cierto sueño que la pasada noche me turbó el alma» en que ve anunciada su muerte por amor (I, 10, 199, la cursiva es mía $)^{17}$.

La necesidad de historias acreditadas en la construcción del sujeto y la constitución del yo en esta época se hace evidente y tiene sus paralelos en otros campos discursivos. En uno de los primeros textos cervantinos, la Información de Argel (1580), leemos cómo el ex-cautivo soldado Miguel de Cervantes construye su propio personaje insistiendo una y otra vez en el crédito de sus doce testigos, mientras acusa a su enemigo, el ex-fraile dominico Juan Blanco de Paz, de desacreditarle ${ }^{18}$. Cito dos apartados del Informe, en su totalidad, para que se aprecie el contexto y el uso de crédito:

XXI yten: si saben o an oydo descir quel dicho dotor juan blanco de paz,
arriba dicho, siendo como hera su enemigo, la qual enemistad se causó por
el dicho juan blanco auer manifestado al dicho rrey Haçan lo de la fragata
que arriba se dixo; y porque el dicho miguel de serbantes se quexava, con

17. Sobre el posible «doble origen histórico» del nombre e identidad del soldado Manuel de Sosa Coitiño ver Armstrong-Roche (2009: 220-221), que también da interesantes perspectivas sobre el crédito en la narrativa «autorial, imperial y épica». Como sabemos, más tarde el grupo de viajeros tendrá la posibilidad de debatir un sueño de Periandro, en II, 15.

18. El texto no está recogido en CORDE. Lo cito aquí por la edición y estudio de Pina Rosa Piras (2014). La Biblioteca Virtual Miguel de Cervantes reproduce la edición de la Información general de Miguel de Cervantes Saavedra ... de la Imprenta de Miguel Quirós de 1864, accesible en: $<$ http://www.cervantesvirtual.com/nd/ark:/59851/bmenp204>. 'Crédito' aparece 8 veces en el conjunto de textos que lo componen. En un artículo, Jesús Villalmanzo da a conocer unos documentos inéditos que ofrecen alguna información nueva sobre el cautiverio de Cervantes, relacionado con el 'redentor' fray Juan Gil y unos mercaderes valencianos, al cual remito para información complementaria (Villalmanzo 2016). 
rrazon, que le auia quitado la libertad a el y a toda la flor de los cristianos cativos de argel, como hera publica voz y fama y cosa muy sabida, el dicho dotor juan blanco, viendose aborrescido de todos, corrido y afrentado, y ciego de la pasion, amenasaua al dicho miguel de serbantes, diziendo que avia de thomar ynformación contra él para hazerle perder el credito y toda la pretension que thenia de que su magestad le auia de facer merced por lo que auia fecho e yntentado de hazer en este argel (Rosa Piras 2014: 102; la cursiva es mía).

\section{En la pregunta XXIII se interroga a los testigos:}

... si saben ó an oydo descir que para hefetuar su mala yntencion, pensando que con esto quitaría el credito al dicho miguel de serbantes, el dicho juan blanco de paz se puso a thomar algunas ynformaciones, como comisario del santo oficio, segun dezia que hera el susodicho, y particularmente contra algunos quien él thenía odio y enemistad hespecial, contra el dicho miguel de serbantes, ynquiriendo de sus uidas y costumbres. digan, etc. (2014: 102, la cursiva es mía) ${ }^{19}$.

En sentido positivo, varios de los testigos que Miguel de Cervantes presenta a su favor en su Información, emplean el vocablo 'crédito' en sus respuestas para afirmar que sus testimonios son avalados por «personas principales de crédito, fidedignas»; mientras el testigo, capitán Domingo Lopino, confirma la crítica de Cervantes contra Juan Blanco, repitiendo el vocablo en su respuesta a la penúltima pregunta: «Este testigo le tiene y tubo por hombre de mala rreputación y poco crédito» (Rosa Piras 2014: 129).

Algunos críticos consideran la Información la «primera ficción» de Miguel de Cervantes, aunque es también un testimonio oficial notarial, como nos lo recuerda María Antonia Garcés en su estudio sobre Cervantes in Algiers (2002: 99) ${ }^{20}$. No olvidemos que la reintegración del cautivo como sujeto en la sociedad dependía de su historia acreditada ${ }^{21}$. Esto también fue una cuestión

19. Carroll B. Johnson sostiene que «no hay ninguna diferencia fundamental entre la construcción del personaje textual llamado "Serbantes" y el llamado "don Quijote" por sus respectivos narradores y compañeros de texto» (1995: 30). Y concluye: «En última instancia, Cervantes no ofrece personajes, sino la posibilidad de construir vidas. (...) [lo que] supone un proceso histórico de existencia en el tiempo, en relación dialéctica con la situación y persona-persona» más que «personaje literario» (32).

20. Para la lectura de la Información como texto de ficción autobiográfico, ver por ejemplo Pina Rosa Piras (2001: 129) y su edición y estudio posterior (2014). También Garcés comenta que es su "first prose composition, a narrative complete with sections or "chapters"» (2002: 116). Para una discusión de este texto dentro de la historia del género novelesco, ver Goodwin (2006).

21. Otro «eslabón» potencialmente interesante en la historia de la constitución del sujeto y construcción del yo en los siglos XVI-XVII, que guarda una relación con el protagonista del Persiles y su autor, serían «los relatos épicos y memorialísticos» de la soldadesca de los Austrias en el Mediterráneo. Se suele advertir que en los relatos de tales «casos» o «sucesos» el protagonista es colectivo y no individual, y que a pesar de ser autores y narradores, no son protagonistas de sus propias historias, y que por lo tanto no «apuntan» hacia la autobiografía moderna, ver Miguel Martínez (2014: 108). Sin embargo, Martínez cuestiona qué ocurre cuando el soldado autor y narrador también «se postula» como protagonista, y sugiere que estos textos quedan «a medio camino» entre la «épica militar impresa» y la «autobiografía picaresca manuscrita» (2014: 120). Estos textos presentan «los esfuerzos 
de crédito económico, relativo al pago de rescate. Los familiares de los cautivos acudían a todas las instancias a su alcance para recaudar los fondos necesarios para dicho fin. Como es sabido, en el caso del rescate de Cervantes el precio fue fijado en «quinientos escudos de oro en oro de España», que el fraile trinitario Juan Gil logró comprar de unos mercaderes para pagar el rescate el mismo día que Cervantes iba a ser transferido a Constantinopla, consiguiendo así su libertad (Garcés 2002: 108-109)22.

El segundo ejemplo de la necesidad de historias acreditadas nos traslada a las letras inglesas, pero valga el ejemplo aquí para ilustrar la relación íntima entre el crédito y la narrativa con el oro como eslabón necesario. Me sirvo aquí de un artículo de Martin N. West, quien muestra cómo el explorador Walter Raleigh «convierte su narrativa en crédito» cuando se dirige al monarca Jaime I para financiar sus futuros viajes. Raleigh ha traído muy pocas muestras de riqueza en forma de metal, pero el explorador, soldado, poeta, cortesano y aristócrata sabe que «el valor del oro guyano [...] está en función de la creencia que Jaime tiene en él», y por lo tanto pone toda su confianza en su propia capacidad narrativa produciendo una especie de «retórica de la inflación» (West 1997: 315, mi traducción). Raleigh se construye y se constituye como explorador y sujeto acreditado mediante sus historias sobre la riqueza potencial (lo que, como sabemos, al final no le salvó de la decapitación un año antes (1618) de que el Persiles aparezca en inglés).

Esta confianza en su propia capacidad narrativa la vemos celebrada en otro pasaje del Persiles cuando los falsos cautivos se defienden de los alcaldes ex-cautivos, contando cómo han invertido en el lienzo y en la información sobre Argel que consideran suficiente para «acreditar nuestro embeleco» (III, 10, 535). Además, no dudan en constituirse como sujetos acreditados en la sociedad a diferencia de «los que cohechan, los escaladores de casas, los salteadores de caminos, los testigos falsos por dineros, los mal entretenidos de la república, los ociosos y baldíos en ella» (537). Quedan admirados Periandro y los demás peregrinos de su industria e ingenio, y el alcalde les hace esta pregunta tan significativa en cuanto a creencia y crédito, pidiéndoles su 'tarjeta de crédito', podríamos decir: «¿Traéis otra historia que hacernos creer por verdadera, aunque la haya compuesto la misma mentira?» (539).

Así vemos otra vez señalado el intercambio de historias, y en cierta forma cómo el protagonista 'se alimenta' con las historias de los demás. En última instancia todas estas historias forman parte de la construcción de su propio sujeto, o lo que yo definiría como su «yo relacional».

heroicos de los soldados comunes para convertirse en autores, los autores de su propia identidad social y discursiva» (2014: 121). Nótese que también se ha sugerido que Cervantes en el Persiles, «pese a la centralidad de Periandro y Auristela y a diferencia del Quijote, [configura] un personaje colectivo», Muñoz Sánchez (2015: 262). ¿O tal vez no tanto un personaje colectivo como un 'yo en cadena' o varios 'yoes acreditados' en mayor o menor medida?

22. Ver también la biografía ya citada de Lucía Megías sobre la historia del cautiverio y rescate de Cervantes (2016: 189-261). 
Obviamente, Periandro-Persiles no es 'cualquier yo', sino un sujeto real (en sentido de realeza), y por tanto destinado a gobernar sobre los demás, como súbditos suyos. Sin embargo, precisamente por ello es interesante observar este afán de coleccionar historias durante su largo trayecto como $\mathrm{Pe}$ riandro hasta recobrar, con «intereses» podríamos decir, su identidad real de Persiles. A pesar de que también se puede observar este obrar desde otra perspectiva y cuestionar la «honestidad» de Persiles, y verlo más bien como un «manipulador» de su auditorio, tal como hace Julia D'Onofrio al examinar su sueño o visión alegórica de la Isla de la Sensualidad. No se agota la representación de este 'sujeto real' en ninguna de estas alternativas, como también subraya D’Onofrio (2019) $)^{23}$.

\section{EL YO RELACIONAL Y EL CRÉDITO}

Obviamente, el 'yo' o el 'sujeto' a caballo entre el siglo XVI y XVII no es igual al 'yo' del individualismo decimonónico, pero tampoco es el mismo que el 'yo colectivo medieval'. Y a pesar de haber asegurado en la introducción que no indagaré en detalle la vía psicológica, tengo que permitirme unos breves comentarios aquí sobre este «sujeto en construcción». Un manual de uso de psicología social nos basta para constatar que desde el punto de vista histórico el 'yo' es relativamente reciente, pues se indica el siglo XVI como inicio para los cambios que llevarán hacia un «yo individual complejo» (Hogg y Vaughan 2010: 112) que afrontará posteriormente grandes «fuerzas del cambio» para llegar al yo moderno: secularización, industrialización, ilustración y psicoanálisis ${ }^{24}$, donde notamos que solamente el primero (secularización) tiene su origen en el siglo XVI.

En cuanto a lo que este manual nos ofrece de teorías para «tipos de yo e identidad» (2010: 123), lo más interesante para nosotros es el 'yo relacional' en sus dos vertientes: según su función de identidad social o identidad personal. O sea: el 'yo colectivo relacional' y el 'yo individual relacional'; donde el primero tiene que ver con los atributos que especifican cómo el yo se relaciona con otros miembros de su propio grupo o grupos externos, como en el caso de Periandro y su grupo de peregrinos y sus encuentros con otros; y

23. El marco del estudio que hace D’Onofrio de Periandro en este caso son «las prácticas propagandísticas de autoglorificación cortesana» de la sociedad barroca (2019: 105). Es de notar que Periandro en su narración del episodio del sueño, incluyendo el episodio del náufrago, no se valga del vocablo 'crédito' o 'acreditar' ante su auditorio, pero recuérdese que el narrador al final del capítulo 14 precisa que «cobró aliento Periandro para proseguir su historia en esta forma:» (II, 14, 378, la cursiva es mía), y que Periandro mismo marca de manera explícita su final: «Fue tanto el ahínco que puse en decir esto, que rompí el sueño y la visión hermosa desapareció, y yo me hallé en mi navío con todos los míos, sin que faltase alguno de ellos» (II, 15, 385, la cursiva es mía). Ver también lo que comenta D’Onofrio acerca de incluir el episodio del náufrago en el sueño. 1921.

24. Cf. Freud Massenpsychologie und Ich-Analyse / Psicología de las masas y análisis del yo, 
el segundo tiene que ver con los atributos que especifican la relación entre el yo como individuo único y otros como individuos de su mismo valor, por ejemplo en la comunicación entre Periandro y Auristela, donde Periandro respeta la individualidad y la constitución de Auristela como sujeto libre ${ }^{25}$.

Se ha comentado que Periandro/Persiles es un «mal personaje de novela según parámetros actuales» porque se convierte en «símbolo universal» ${ }^{26}$. Sin embargo, si lo enfocamos «desde el lenguaje mismo de los personajes y narradores», como escribe Steven Hutchinson en la introducción a su libro ya mencionado, me parece que Periandro nos dice muchas más cosas específicas sobre el nacimiento del «yo individual complejo», o sobre la construcción del yo sujeto en la temprana Modernidad. Casalduero (1947) sostenía que en el Persiles domina el monólogo por el furor de las pasiones, a la manera barroca, a diferencia del diálogo renacentista ${ }^{27}$. Y aunque esto parezca contradecir la idea de un protagonista que escucha y admite las historias de los demás, hemos visto que no solamente importa el «derroche de pasiones» desde un 'yo aislado', sino también que los personajes se relacionen entre sí mediante el intercambio de historias que se acreditan de maneras diversas ${ }^{28}$. Recordemos asimismo que el autor en uno de los primeros escritos que tenemos de su mano, el ya referido la Información de Argel, nos ha demostrado la importancia vital de una historia del 'yo' acreditada por testigos.

Como ya indicamos en la introducción, el vocablo 'crédito' destacaba en los campos discursivos de la religión y la economía, los cuales sufrían importantes cambios en la época, la religión enfrentándose al cisma y al escepticismo; mientras el campo discursivo de la economía estaba en vía de constituirse como un campo de conocimiento propiamente dicho. Es bien conocido que Cervantes no era nada ajeno al discurso económico de su tiempo. De hecho,

25. Aquí me limitaré a señalar lo que Armstrong-Roche ha comentado acerca de Periandro como 'yo individual relacional' en su comunicación con Auristela como individuo único. Armstrong-Roche argumenta que la principal virtud de Periandro en Roma es respectar la elección de Auristela de hacerse monja. Respeta su individualidad y libre albedrío como sujeto. Según este estudioso, Persiles tiene el don de saber preguntar y honrar la respuesta de la cuestión fundamental «¿Qué quieres?»; algo que los demás héroes no han sabido preguntar a las que presumen amar (Armstrong-Roche 2009: 101).

26. «La conversión paulatina del personaje en símbolo universal es lo que ha hecho del mismo un mal personaje de novela según parámetros actuales, "sin desarrollos interiores, como pálido fantasma de un mundo de ensueño", según apunta un crítico» [Celestino Capasso en un diccionario literario, 1960] (Cruz Casado 1995: 69).

27. «Los personajes no dialogan como en el Renacimiento; viviendo en la clausura de sus pasiones, se entregan con furor al monólogo. No vacían su corazón para hacerlo entrar en el cauce del diálogo, para encontrar un límite que aclare y ordene sus sentimientos; lo que necesitan es verlo manar a raudales y sentirse arrastrados por su corriente. [...] Es el monólogo del desasosiego y la inquietud del hombre» (Casalduero 1947: 109-110).

28. Jorge Checa ha hecho un examen sobre el lenguaje y la «ética verbal» en el Libro II del Persiles (con referencias interesantes a Erasmo y Castiglione), comentando cómo la dominación racional de la palabra «conlleva en la novela una dimensión social tendente a afirmar el poder y la influencia del hablante sobre su interlocutor. Desde semejante perspectiva, el lenguaje, junto a un don natural entregado gratuitamente al hombre, es un instrumento artificioso y, por ello, susceptible de perfeccionamiento. El desarrollo de este artificio supone una garantía de triunfo» (1985: 148-149, cursiva en el original). 
durante toda una década -de 1588 a 1598- desempeñó el cargo de recaudador de impuestos, o comisario real de abastos, en Andalucía, con lo que esto implicaba en cuanto a la redacción de informes económicos y el manejo de vocabulario específico que el cargo requería (y como sabemos, muchos disgustos, incluso una encarcelación, y puesta en libertad bajo fianza).

\section{CONCLUSIÓN: LA RELATIVIDAD DEL CRÉDITO}

Si volvemos a la historia del bárbaro italiano y nos fijamos en cómo $\mathrm{Ru}-$ tilio termina su historia, «con que dejó admirados y contentos a los oyentes» (I, 9, 194), vemos que vuelve a usar la expresión 'dar crédito': «Con la atención y curiosidad, noté su lengua y aprendí mucha parte de ella; supe la profecía que de la duración de su reino tenía profetizada un antiguo y sabio bárbaro a quien ellos daban gran crédito» (194, la cursiva es mía).

Aquí estamos ante uno más entre varios ejemplos del vocablo 'crédito' en el Persiles, esta vez relacionado con el ámbito de la religión o de la fe y de la profecía. Sin embargo, dejando al lado la cuestión de la profecía, lo que quisiera señalar es cómo el bárbaro italiano, a quien Periandro ha otorgado el crédito de su historia, aquí nos enseña la relatividad del crédito, ya que comenta cómo también los 'verdaderos bárbaros' se constituyen y construyen como sujetos acreditados. No me parece en balde señalar este detalle ante la 'acreditación' más llamativa y comentada del mundo bárbaro, la de la bárbara Ricla en su declaración del credo:

[D]éjame a mi que cuente lo que queda, a lo menos hasta este punto en que estamos. -Soy contento -respondió el español-, porque me le dará muy grande el ver como lo relatas.

- Es, pues, el caso -replicó la bárbara- que mis muchas entradas y salidas en este lugar le dieron bastante para que de mí y de mi esposo naciesen esta muchacha y este niño. Llamo esposo a este señor, porque, antes que me conociese del todo, me dio palabra de serlo, al modo que él dice que se usa entre verdaderos cristianos. Hame enseñado su lengua, y yo a él la mía, y en ella ansimismo me enseñó la ley católica cristiana. Diome agua de bautismo en aquel arroyo, aunque no con las ceremonias que él me ha dicho que en su tierra se acostumbran. Declaróme su fe como él la sabe, la cual yo asenté en mi alma y en mi corazón, donde le he dado el crédito que he podido darle. Creo en la Santísima Trinidad, [...] Con éstas me ha enseñado otras cosas, que no las digo por parecerme que las dichas bastan para que entendáis que soy católica cristiana (I, 6, 176-177, la cursiva es mía).

Ricla se constituye y se construye como yo al «dar crédito» a su Credo con sus propias palabras, pronunciadas en la lengua aprendida de su esposo español ${ }^{29}$.

29. Otro aspecto de la «credibilidad» del personaje de Ricla se discute en Davenport (2019). 
En conclusión, este vocablo tan frecuente en la obra cervantina parece haberle prestado un servicio particular al autor en la construcción de sus personajes, permitiéndoles a ellos constituirse a sí mismos y relacionarse entre sí. Al rastrear y enfocar el uso de 'crédito' y sus derivaciones en el Persiles hemos podido observar cómo Cervantes aprovecha para sus fines narrativos todas las sutilezas del vocablo, tal como se lo prestaron, entre otros, los discursos religiosos y económicos eminentemente modernos de su tiempo.

\section{APÉNDICE}

1. 'CRédito' en Corominas, Covarrubias, DicCionario de Autoridades [resumo y modernizo]. El Diccionario de construcción y régimen de la lengua castellana. Tomo II (1998) de José Rufino Cuervo no ofrece una entrada sobre 'crédito', pero en las entradas CREDULIDAD, CRÉDULO, CREER, abundan los ejemplos de la obra cervantina en su conjunto.

Corominas: CREER, del lat. CREDERE, 'creer, dar fe (a alguno)', 'confiar en préstamo, prestar'. Primera documentación en el Cid. [...] Cultismos: [...] crédito [S. XVI, antes de $1568 \ldots]$, tomado del latín creditum 'préstamo, deuda', participio neutro de credere; por lo menos en sentido mercantil es probable que viniera por conducto del italiano, donde ya se halla en 1409; [...]. Credo [1565-1566, Sta. Teresa], de credo, primera persona singular del presente de indicativo, del verbo latino, con la cual empieza esta oración (1996: 235).

Covarrubias: CREDITO. La credulidad que damos a lo que se nos dice. Crédito, buena opinión y reputación. Crédito, entre mercaderes, abono de caudal y correspondencia con los demás. [...] CREER. Latine CREDERE, asentir con lo que no entendemos o sentimos, propio acto de la fe. [...] En las cosas humanas [...]. El creer es cortesía, entiéndese [sic] de las tejas abajo.

Diccionario de Autoridades: CREDIBILIDAD. Creencia, crédito, fe y verisimilitud. Es voz formada y sacada del latino Credibilis. Lat. Credibilitas, tis. [...] CREDITO, La fe o creencia, y ascenso firme que se da a lo que otro dice. Es del latino Credere. Lat. Fides. Nieremberg Obras y dias, cap. 5. «Porque el que cree a otro hombre, no lo hace sin que acompañe a su crédito alguna razón que divise el bulto de la verdad». [...] CREDITO. Por extensión significa seguridad, apoyo, abono, firmeza y comprobación de alguna cosa: y así comúnmente se dice, en crédito de esta verdad, noticia, suceso, y así de otras varias cosas: esto es, en abono, seguridad y certeza de ellas, etc. [...] CREDITO. Vale también estimación, buena opinión, fama y reputación. [...] CREDITO. Escritura, papel o vale de alguna cantidad de dinero, o cosa equivalente que uno debe a otro, y a que el acreedor tiene justo y claro derecho para poderla pedir y cobrar. [...] CREDITO. Se llama también la libranza o abono que da el hombre de comercio a alguna persona, para que otro le 
dé alguna cantidad de dinero u otra cualquier cosa que pidiere, a cuya satisfacción queda obligado [...] (1976: 652-653).

\section{2.a EXPRESIONES CON 'CRÉDITO' EN EL PERSILES}

Ed. Carlos Romero Muñoz, Madrid, Castalia, 5. a ed., 2004. Se remite al libro, capítulo y página. Son 24 ocurrencias del vocablo ‘crédito’ en total.

- La bárbara Ricla (I, 6, 178)

- $\quad$ El (bárbaro) italiano Rutilio (I, 7, 184; I, 9, 194)

- El enamorado portugués Manuel de Sosa Coitiño (I, 10, 199)

- $\quad$ El astrólogo Mauricio (a Clodio el maldiciente inglés) (I, 18, 247 y 248)

- $\quad$ Sinforosa, la hija de Policarpo (a Auristela) (II, 3, 296)

- $\quad$ Auristela (a Sinforosa) (II, 3, 297)

- $\quad$ Policarpo (a Sinforosa) (II, 5, 304)

- Rutilio en carta a Policarpa (II, 7, 317)

- Auristela a Clodio (por el papel escrito) (II, 8, 328)

- Periandro a su auditorio [crédito + cortesía, nota de Romero] (II, 12, 362)

- $\quad$ Feliciana de la Voz (III, 3, 453)

- $\quad$ Periandro a la hermosa zagala (III, 12, 556)

- Ambrosia Agustina (a su hermano / y a los peregrinos) (III, 12, 562, y 563: «creer es cortesía»)

- $\quad$ Serafido a Rutilio (IV, 13, 705)

- El narrador, con 4 o 5 casos según incluimos uno en que el narrador le pone en boca de Periandro al polaco Ortel Banedre [crédito + cortesía] (III, 6, 490); y también el narrador sobre Periandro (II, 20, 415); el narrador sobre la Virgen de Guadalupe (III, 5, 472); el narrador en primera persona (III, cap. 16, 583); el narrador sobre «el que escribió esta historia dice que Soldino...» (III, 18, 601); el narrador sobre el pensar colectivo en (III, 19, 605)

También hay un caso con 'créditos' en plural:

- Rosamunda a Clodio: «Tú has lastimado mil ajenas honras, has aniquilado ilustres créditos» (I, 14, 224)

2.b EJEMPLOS CON 'ACREDITAR' y SUS DERIVACIONES EN EL PERSILES

El primer número entre paréntesis refiere al número de casos de cada variante. Son 26 casos en total.

- 'acreditaban' (1: I, 5, 307 narrador refiriendo Sinforosa a Policarpo)

- 'acreditada' (3: II, 8, 331 Cenotia; III, 4, 458 Auristela a/sobre Periandro; III, 19, 605 narrador)

- ' 'acreditan' (1: II, 13, 368 Leopoldio, rey de los dáneos a Periandro y sus piratas) 
- 'acredite' (1: II, 18, 403 Sulpicia a Cratilo)

- 'acreditaría' (1: II, 19, 409 Renato cuenta su historia)

- 'acreditado' (1: II, 20, 415 narrador sobre el crédito de Periandro y duda de Mauricio)

- 'acreditar' (3: II, 20, 415 Periandro sobre el caballo de Cratilo; III, 4, 463 narrador sobre Feliciana; III, 10, 535 los cautivos falsos)

- ' 'acreditarle' (1: II, 21, 420 narrador-yo sobre Auristela)

- 'acreditasen' (1: III, 4, 459 Periandro a Auristela)

- 'acreditaran' (1: III, 4, 459 Periandro a Auristela)

- 'acreditarla' (1: III, 4, 463 narrador sobre Feliciana)

- 'acreditó' (3: III, 5, 473 narrador sobre Feliciana; III, 18, 599, narrador sobre Soldino; IV, 10, 689, narrador sobre Auristela)

- 'acreditándole' (1: III, 10, 535 los cautivos falsos)

- 'acreditadas' (1: III, 16, 585 la Talaverana a los peregrinos)

- 'acreditaron' (1: III, 16, 586 narrador refiriendo a Periandro, Auristela y Constanza sobre la perdida moza)

- 'se acredita' (1: III, 16, 584 la Talaverana a los peregrinos)

- 'acreditarme' (1: III, 18, 598 Soldino a la dueña del mesón y los peregrinos)

- 'acredité' (1: III, 18, 603 Ruperta a Croriano)

- 'acreditarlas' (1: III, 18, 599 narrador sobre las voces que gritando fuego)

- ' 'acreditéis' (1: III, 20, 617 Isabela Castrucha «que acreditéis mi mentira»)

Añadimos al final también el ejemplo de 'crédulos' en el Persiles (CORDE da La Galatea como único otro ejemplo de este vocablo en la obra cervantina): el príncipe danés Arnaldo agradece a Mauricio la «explicación científica» que ofrece sobre la licantropía después de escuchar lo que narra Rutilio: «Gusto me ha dado grande - dijo Arnaldo- el saber esta verdad, porque también yo era uno de los crédulos deste error; y lo mismo debe ser lo que las fábulas cuentan de la conversión en cuervo del rey Artus de Inglaterra, tan creída de aquella discreta nación, que se abstienen a matar cuervos en toda la isla» (I, 18, 246-247).

\section{BIBLIOGRAFÍA CITADA}

Armstrong-Roche, Michael (2009). Cervantes' Epic Novel. Empire, Religion, and the Dream Life of Heroes in Persiles. Toronto: University of Toronto Press.

Casalduero, Joaquín (1947). Sentido y forma de "Los trabajos de Persiles y Sigismunda". Buenos Aires: Editorial Sudamericana.

Castiglione, Baltasar de (1984). El cortesano, ed. Rogelio Reyes Cano, 5. ${ }^{\text {a }}$ ed. Madrid: Espasa-Calpe. Colección Austral, p. 549.

Cervantes, Miguel de (2004). Los trabajos de Persiles y Sigismunda, ed. Carlos Romero Muñoz, 5. ${ }^{\mathrm{a}}$ ed. Madrid: Cátedra. 
Checa, Jorge (1985). «Lenguaje y ética verbal en el libro II del Persiles», Anales Cervantinos. 23, pp. 133-150.

Corominas, Joan y José A. Pascual (1980). Diccionario crítico etimológico castellano e hispánico. Madrid: Editorial Gredos, vol. 2: CE-F.

Covarrubias Horozco, Sebastián de (2006). Tesoro de la lengua castellana o española, Ignacio Arellano y Rafael Zafra (eds.). Madrid: Iberoamericana.

Cruz Casado, Antonio (1995). «Periandro-Persiles: las raíces clásicas del personaje y la aportación de Cervantes», Cervantes: Bulletin of the Cervantes Society of America. 15 (1), pp. 60-69.

Davenport, Randi Lise (2019). «Dando crédito al Septentrión: Ricla y el naufragio de Pietro Querini en la isla de Røst», Hipogrifo. Revista de literatura y cultura del Siglo de Oro. 7 (1), pp. 59-71. https://doi.org/10.13035/H.2019.07.01.07.

Deffis de Calvo, Emilia I. (1990). «El cronotopo de la novela española de peregrinación: Miguel de Cervantes», Anales Cervantinos. 28, pp. 99-198.

Diccionario de Autoridades (1990). Edición Facsímil, Real Academia Española. Madrid: Editorial Gredos, 3 vols.

D’Onofrio, Julia (2019). «“Un escuadrón de hermosísimas, al parecer, doncellas...”: Periandro narrador y la manipulación del espectáculo barroco», en Randi Lise Davenport e Isabel Lozano-Renieblas (eds.), Cervantes en el Septentrión. Nueva York: Instituto de Estudios Auriseculares, pp. 103-119. Accesible en: <https:/www.unav.edu/web/ griso/publicaciones/coleccion-batihoja>.

Egido, Aurora (1991). «El Persiles y la enfermedad de amor», en Actas del II Coloquio Internacional de la Asociación de Cervantistas. Alcalá de Henares: Asociación de Cervantistas - Anthropos, pp. 201-224.

Egido, Aurora (2004). «Los trabajos en el Persiles», en Alicia Villar Lecumberri (ed.), Peregrinamente peregrinos. Actas del V Congreso Internacional de la Asociación de Cervantistas. Palma de Mallorca: Asociación de Cervantistas, vol. I, pp. 17-66.

Fernández-Flores Funes, Francisco (2016). Los tributos, la moneda y el crédito en el Quijote. Madrid: Marcial Pons.

Forcione, Alban K. (1970). Cervantes, Aristotle and the 'Persiles'. Princeton: University Press.

Garcés, María Antonia (2002). Cervantes in Algiers. A Captive's Tale. Nashville: Vanderbilt University Press.

González Rovira, Javier (1996). La novela bizantina de la edad de oro. Madrid: Gredos.

Goodwin, Robert T. C. (2006). «Origins of the Novel in Cervantes's Información de Argel», Bulletin of Hispanic Studies. 83, pp. 317-336.

Hogg, Michael A. y Graham M. Vaughan (2010). Psicología social, 5. ed. Buenos Aires: Editorial Médica Panamericana (original inglés 2008).

Hutchinson, Steven (2001). Economía ética en Cervantes. Alcalá de Henares: Centro de Estudios Cervantinos.

Johnson, Carroll B. (1995). «La construcción del personaje en Cervantes», Cervantes: Bulletin of the Cervantes Society of America. 15 (1), pp. 8-32.

Kenny, Neil (1998). Curiosity in Early Modern Europe: Word Histories. Wiesbaden: Harrasowitz.

Kitch, Aaron (2009). Political Economy and the States of Literature in Early Modern England. Londres: Routledge. https://doi.org/10.4324/9781315601175.

López Navia, Santiago (2004). «Pseudohistoricidad y pseudoautoría en el Persiles. Límites y relevancia», en Alicia Villar Lecumberri (ed.), Peregrinamente peregrinos. Actas del V Congreso Internacional de la Asociación de Cervantistas. Palma de Mallorca: Asociación de Cervantistas, vol. I, pp. 457-482. 
Lozano-Renieblas, Isabel (1998). Cervantes y el mundo del Persiles. Alcalá de Henares: Centro de Estudios Cervantinos.

Lozano-Renieblas, Isabel (2014). Cervantes y los retos del «Persiles». Salamanca: SEMYR.

Lucía Megías, José Manuel (2016). La juventud de Cervantes. Una vida en construcción. Madrid: Edaf.

Lukens-Olson, Carolyn (2001). «Heroics of Persuasion in Los Trabajos de Persiles y Sigismunda», Cervantes: Bulletin of the Cervantes Society of America. 21 (2), pp. 51-72.

Martín Morán, José Manuel (2008). «El género del Persiles», Cervantes: Bulletin of the Cervantes Society of America. 28 (2), pp. 173-193.

Martínez, Miguel (2014). «La vida de los héroes: épica y autobiografía en el Mediterráneo Habsburgo», Caliope. 19 (1), pp. 103-128.

Mercado, Tomás de (1571). Summa de tratos y contratos [...] Añadidas a la primera eddicion, muchas nueuas resoluciones. $Y$ dos libros enteros [...]. Sevilla: Hernando Diaz Impressor de Libros.

Moner, Michel (1989). Cervantès conteur. Écrits et paroles. Madrid: Casa de Velázquez.

Muñoz Sánchez, Juan Ramón (2015). «Reflexiones sobre Los trabajos de Persiles y Sigismunda, historia setentrional», Anales Cervantinos. 47, pp. 249-288. https://doi. org/10.3989/anacervantinos.2015.009.

Nieremberg, Juan Eusebio (1629). Obras y dias: manual de señores y príncipes. En que se propone con su pureza y rigor la especulacion y execucion politica, economica $y$ particular de todas virtudes. Madrid: Viuda de Alonso Martín.

Quirós García, Mariano (2013). «La cuestión de la lengua en el discurso tecnocientífico español del siglo XVI: el ejemplo de la economía», Corpus Eve (en línea), La défense de la langue vernaculaire en Espagne (XVe-XVIIe siècles): paratextes et textes. https:// doi.org/10.4000/eve.857.

Rosa Piras, Pina (2001). «Cervantes, la Información en Argel entre ficción y documento» en Antonio Bernat Vistarini (ed.), Volver a Cervantes. Actas del IV Congreso Internacional de la Asociación de Cervantistas. Palma: Universitat de les Illes Balears, pp. 123-130.

Rosa Piras, Pina (2014). La Información en Argel de Miguel de Cervantes: entre ficción y documento. Alcalá de Henares: Biblioteca de Estudios Cervantinos, Universidad de Alcalá.

Villalmanzo, Jesús (2016). «Cervantes, fray Juan Gil y los mercaderes valencianos», Anales Cervantinos. 48, pp. 53-101. https://doi.org/10.3989/anacervantinos.2016.002.

West, William N. (1997). «Gold on credit: Martin Frobisher's and Walter Raleigh's economics of evidence», Criticism. 39 (3), pp. 315+. Literature Resource Center. Accesible en: $<$ https://link.gale.com/apps/doc/A20167522/LitRC?u=unitroms\&sid=LitRC\&x id $=5$ fd 9 ab $15>$.

Recibido: 14 de marzo de 2018

Aceptado: 4 de septiembre de 2019 